\title{
How treatment epidemiology can shape future healthcare research
}
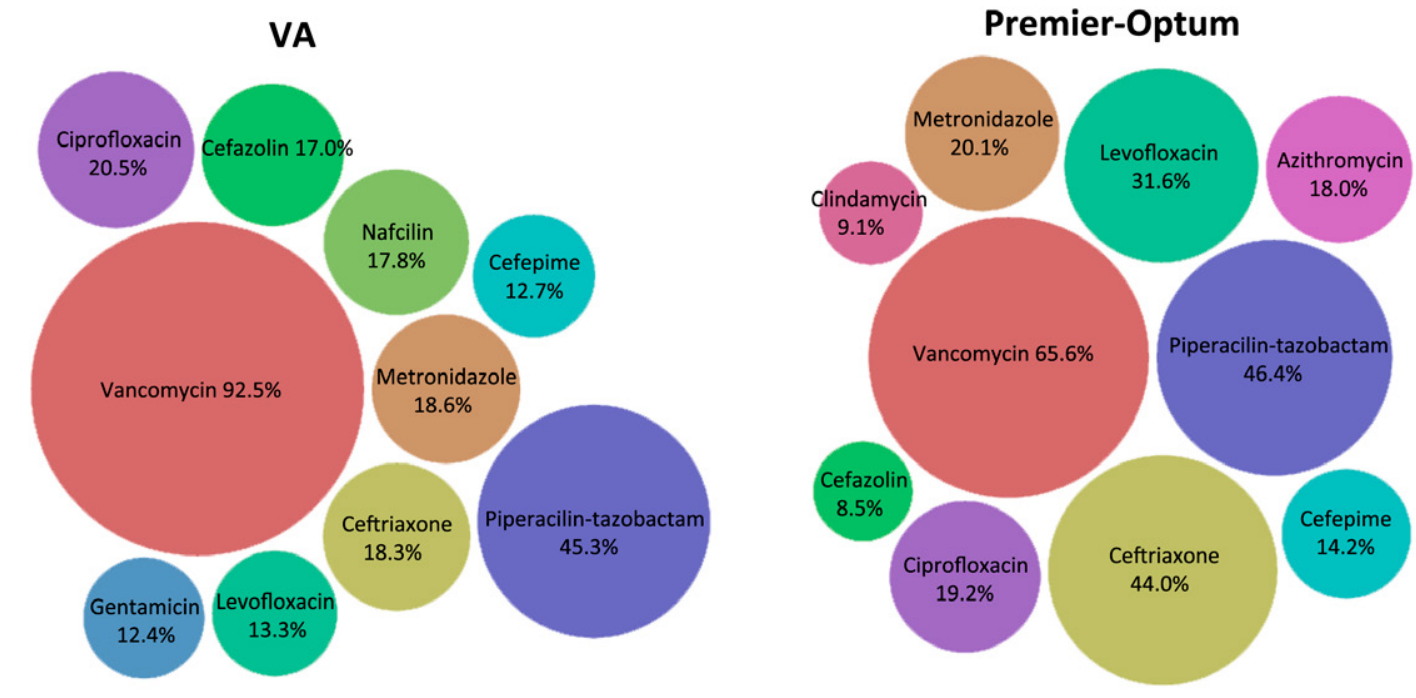

$\begin{array}{ll}\text { Dr Aisling Caffrey is an } & \text { pidemiology can be defined as } \\ \text { Associate Professor of Health } & \text { 'the study of what comes upon } \\ \text { Outcomes at the College } & \text { the people' (from the Greek epi- } \\ \text { of Pharmacy, University of } & \text { demos-logos) and is best known as the } \\ \text { Rhode Island. For over a } & \text { science underpinning public health. } \\ \text { decade, Dr Caffrey has been } & \text { Historically, epidemiology has focused on } \\ \text { studying the treatment of } & \text { the surveillance of disease, also referred } \\ \text { diseases in real-world clinical } & \text { to as ddisease epidemiology', studying } \\ \text { practice, an area Dr Caffrey } & \text { what level of disease occurs and in which } \\ \text { has termed 'treatment } & \text { populations. Disease epidemiology } \\ \text { epidemiology'. Dr Caffrey's } & \text { identifies changes in disease over time, as } \\ \text { expertise is in comparative } & \text { well as risk factors for disease occurrence, } \\ \text { effectiveness and safety } & \text { and disease prevention efforts. As science } \\ \text { research, where she studies } & \text { and medicine have evolved, a natural } \\ \text { the benefits and harms of } & \text { extension of disease epidemiology is } \\ \text { healthcare interventions, } & \text { the study of how diseases are treated, } \\ \text { including medications } & \text { a subject area which Dr Aisling Caffrey, } \\ \text { administered in hospital } & \text { University of Rhode Island, has coined } \\ \text { or long-term care settings, } & \text { 'treatment epidemiology'. This field of } \\ \text { and prescriptions dispensed } & \text { study has a number of different names, } \\ \text { in outpatient settings. } & \text { including pharmacoepidemiology, health } \\ & \text { services research, real-world evidence, } \\ & \text { outcomes research, health outcomes } \\ & \text { research, or pharmaceutical/device } \\ & \text { health outcomes research. Most simply, } \\ \text { this field studies the effects of healthcare }\end{array}$

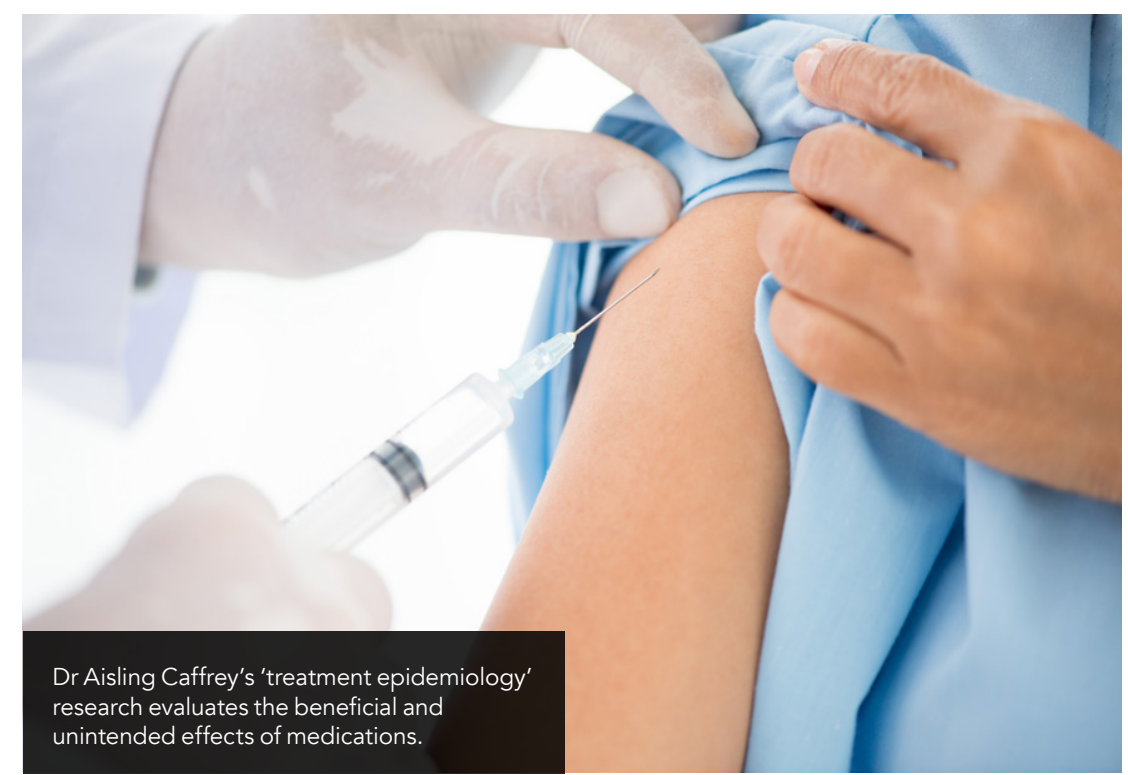

interventions to treat disease, and all these other terms fall under the umbrella of 'treatment epidemiology'.

TREATMENT EPIDEMIOLOGY

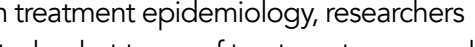
induding medications, medical devices, and alternative therapies, as well as other health senices and health-systen interventions Treatment epidemiology studies how these treatments are prescribed by providers; for example, whether they are prescribed according to clinical guidelines or based on indications approved by drug authorities, and how they are used by patients, such as whether they are being refilled on time. Treatment epidemiology also studies the benefits and harms of treatments. These studies investigate whether medications are working in real-world clinical practice as they were intended to work, by alleviating symptoms or improving clinical measurements, without causing significan

An important aspect of understanding how treatments work in real-world dincal practice is understanding how treatment of the same disease. Patients may wonder why they were prescribed a certain medication for their high cholesterol, whereas their family members or neighbours were prescribed something different for the same condition. We call Medication utilisation in real-world clinical practice and the magnitude of treatment heterogeneity, including the way providers and patients arrive at treatment decisions, assumptionderstood. There is an assumption that patients with a specific condition receive approximately the same
treatment, particularly if clinical guidelines
DrCaffrey aims to improve our antibiotic per number of bacteraemia admissions (Veterans Affai
Pharmacoepidemiol Drug Saf. 2019;1-9. DOI: $10.1002 /$ pds. 4761 .

exist. However, Dr Caffrey's recent work shows that in fact, even patients treatments. "Therefore, there is a need to better understand what treatment in rea world clinical practice actually looks like across diverse clinical settings and diverse patient populations, to inform the design of future research."

\section{TREATMENT HETEROGENEITY} AND EXPOSURE MAPPING

Dr Caffrey has developed methods that allow her to identify patterns of which medications are being used to treat specific diseases, called exposure mapping. "In exposure mapping, all treatments for a specific disease are mapped out for each patient over a period of days or monhs, depending on the expected durtion of treatment." " This treatment petters, induding treatments used in combination and changes in treatments over time DrCafrey has applied these methods to study antibii treatment patterns for serious bacterial infections. This is particularly important as antibiotic resistance continues to grow, and there is often a lack of evidence regarding the safest and most effective antibiotic regimens. Serious bacterial the cause of the infection is unknown during the initial period of treatment and clinical symptoms change day-to-day, which leads to mulliple changes in therapy every few days. This creates barriers to accurately defing antibiotic exposures in infectious diseases and linking spect

Over 50,000 hospitalisations with understanding of treatment patterns using changes in antibiotic therapy, 95 had projects described unique treatment patterns among patients with bloodstream $\quad(88.5 \%)$ and without $(11.5 \%)$ changes infections. This study used a retrospective in therapy overall, only $14 \%$ had the cohort study design to analyse same treatment pattern as another hospitalisations at Veterans Affairs Medical hospitalisation. This study was the first of Centres and community hospitals which its kind, revealing a significant amount of

In exposure mapping, all treatments for a specific disease are mapped out for each patient over a period of days or months, depending on the expected duration of treatment.

had already occurred between 2002 and 2015. The Veterans Health Administration represents a US agency that provides healthcare services to military Veterans. bloodstream infections, also known analysis. Dr Caffrey found that "for every

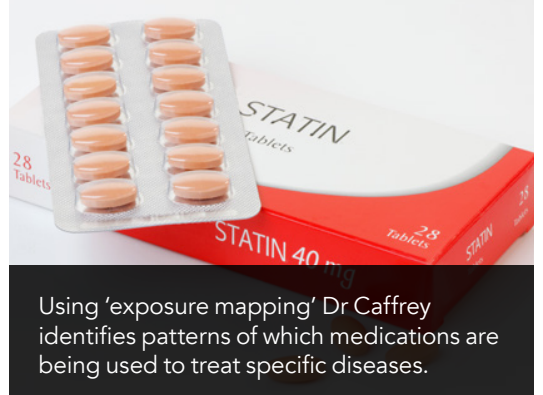

theterogeneity for bloodstrean ing organism (ie Staphylococcus aureus) Dr Caffrey has identified similar levels of extensive treatment heterogeneity in othe infection types (e.g. pneumonia), and with other organisms (e.g. Pseudomonas aeruginosa). This work uncovers the

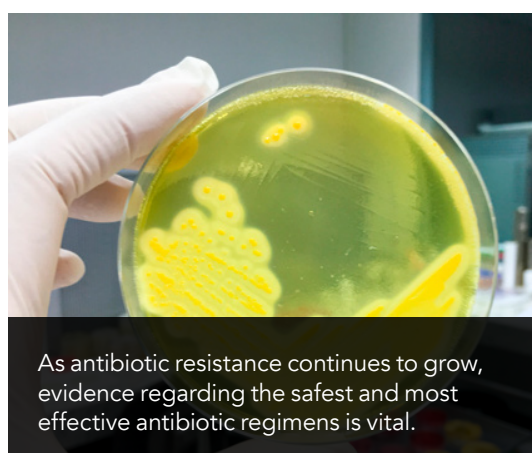



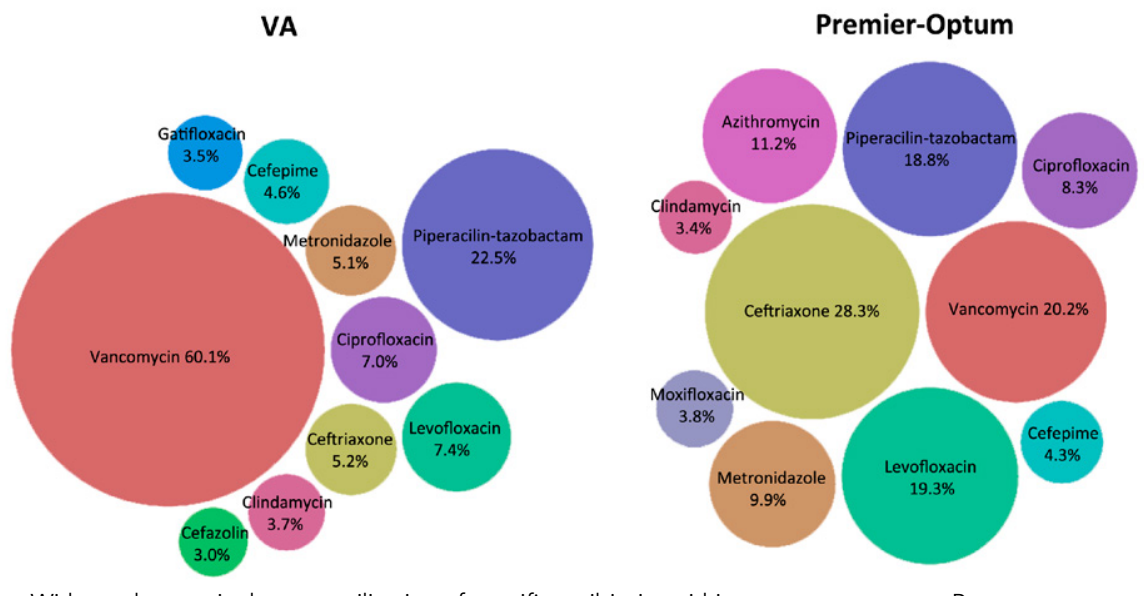

Without changes in therapy: utilisation ot specitic antibiotics within treatment patterns. Percentages

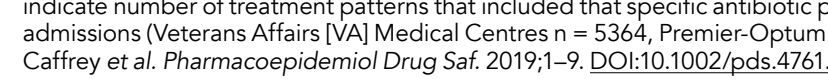

inaccuracy of commonly used definitions of treatment in infectious diseases research.

\section{SERIOUS INFECTION AND}

\section{ICATION}

Other work done by Dr Caffrey has

investigated the potential protective

effects of statins, a medication normally

used to lower cholesterol levels, in

infectious diseases. Many of the existing

studies show varying results and $\mathrm{Dr}$

to differences in exposure time to statins,

and when treatment was started in relation

to the onset of infection. Therefore,

the effect of statins on serious infections,

investigating whether statin use was

continued throughout periods of serio

illness, and if so, what was the impact

of this contine, watin use.

One of Dr Caffrey's studies assessed the impact of continuing or discontinuin statin therapy during hospitalisations bocterium called Staphs caused by a This study was conducted among Veterans Affairs patients and continuation of statin therapy was associated with significant beneficial effects on mortality DrCaffrey found that one death could be prevented in the first month after infection by continuing statin therapy in 10 patients during their hospitalisation.

Dr Caffrey's other exposure mapping work has shown that such hospitalisations for serious bacterial infections interrupt chronic disease medications, resulting in treatment heterogeneity. When evaluat the month before hosptalisation and

For every 100 bacteraemia

hospitalisations with changes in antibiotic therapy, 95 had unique antibiotic treatment patterns.

Frequency of different statin medication and dose treatment patterns before and after hospitalisation ospitalised with Staphylococcus aureus of patients continued the same stan medication and dose for the 61-day observation period. A small proportion, around $7 \%$, of patients had their statin drug or dose changed during the observation period. Statins were initited in $10 \%$ of patients, and also discontinued in a similar proportion of patients. Overall, two thirds of patients experienced changes to their statin therapy, whether this was a discontinuation of the drug, a gap in therapy, or a change in the drug or dose used. This study provides an example of how exposure mapping could be used to improve operationa definitions of exposure. In this case, how statin use changes before and infection hese patterns of medication utilisation Wlimately improves research in in this fion allowing the identification of effective and safe healthcare interventions and enabling the discovery of better ways to treat diseases in the future.

\section{CONCLUSIONS}

Dr Caffrey concludes: "We have a limited understanding of how diseases are really treated in clinical practice, including which medications are commonly used, at which doses, and when changes in reatment are made. "When substantial treatment heterogeneity exists, meaning few patients receive the same treatment, it can be difficult to draw accurately defining treatment by using overly broad definitions. More specific treatment definitions, utilising exposue mapping and accounting for treatment heterogeneity, enable direct comparisons between patients but until these method are implemented across the board, such studies should be interpreted with caution.

To improve upon this, Dr Caffrey has created the RX-OME Project'in, "to discover the nature of variability in drug prescriptions". The RX-OME Project'M will use exposure mapping to identify pattens of usage for medications, including doses and duration of use. Learning more about the nature of treatment variability will help researchers design better studies and practices and clinical guidelines.

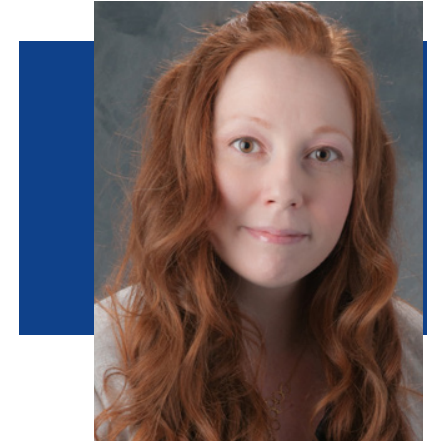

\section{Behind the Research} Dr Aisling Caffrey

E: Aisling_Caffrey@uri.edu T: $+1-401-874-5320$ (Office)
w: https://works bepress.com/aisling caffrey/

\section{Research Objectives}

Dr Caffrey has developed a research programm focused on evaluating the beneficial and unintended drug-resistant bacterialinfections and vaccine-preventable diseases.

\section{Detail}

Aisling Caffrey

7 Greenhouse Road

Kingston

Rhode Island 02881 USA

Bio

Dr Caffrey is an Associate Professor of Health Outcomes in the College of Pharmacy at the University of Rhode Island. She is Director of Infectious Diseases Outcomes Research and Chair of the Institutional Review Board at the Providence Veterans Affairs in in the Department of Health Services, Policy, and Practice at the Brown School of Public Health.

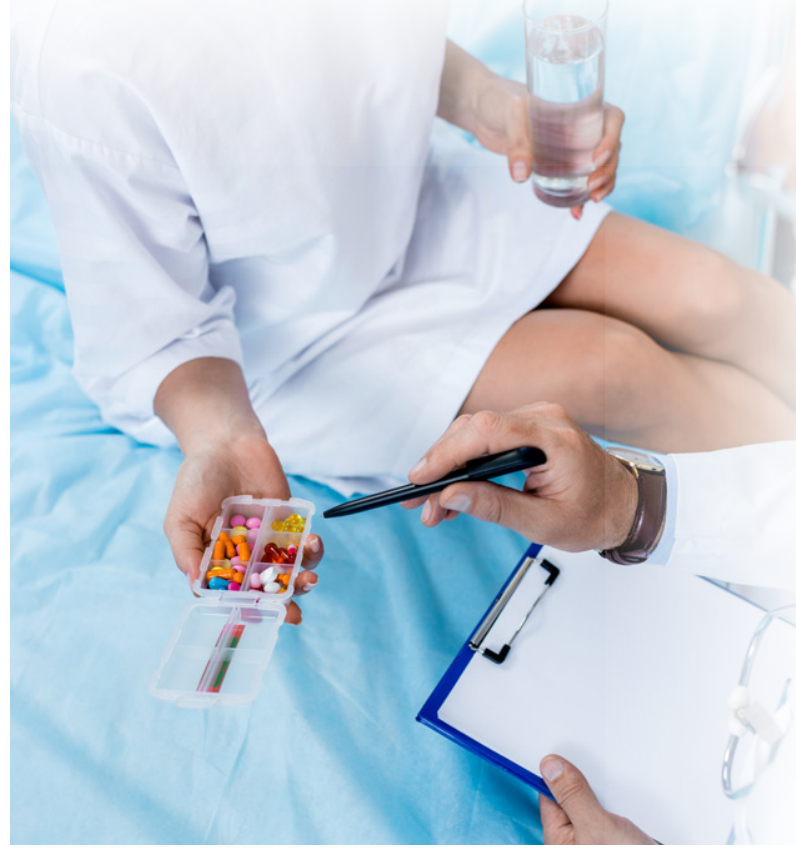

\section{References}

Caffrey, AR, Babcock, ZR, Lopes, W, Timbrook, TT \& LaPlante, KL. (2017). Heterogeneity in the treatment of bloodstream infections identified from antibiotic exposure mapping. Pharmacoepidemiol Drug Saf. 1-9, doi:10.1002/ pds.4761

Caffrey AR, Timbrook TT, Noh E, Sakoulas G, Opal SM, Nizet V, LaPlante KL. (2017). Evidence to support continuation of statin therapy in patients with

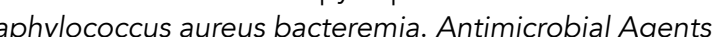
and Chemotherapy. 61(3):e02228-16

\section{Personal Response}

\section{Can you tell us more about the RX-OME Project ${ }^{T M}$ ?} II The idea for this project actually came to me severa years ago. In all of my studies, treatment in real-world
clinical practice was highly variable among patients with the same condition, and also differed from treatment regimens used in clinical trials. We just don't have a good understanding of how diseases are treated, which So under the RX OME ProjectTh, wa So under the RX-OME Project', we are creating an of trends in medication utilisation over time. If we can show how diseases are really treated, for example, which medications are used, at which doses, and for how long, as well as patterns of change in treatment information to better inform researchers. The RX-OME Project T'M also benefits patients, as they can compare what they are taking with national trends in the treatment of their condition.

To learn more about the RX-OME Project, please visit

THE

UNIVERSITY

OF RHODE ISLAND

COLLEGE OF

PHARMACY 